\title{
Anti-Müllerian hormone: a new marker for ovarian function
}

\author{
Jenny A Visser, Frank H de Jong, Joop S E Laven ${ }^{1}$ and Axel P N Themmen \\ Department of Internal Medicine and ${ }^{1}$ Division of Reproductive Medicine, Department of Obstetrics and \\ Gynaecology, Erasmus MC, PO Box 1738, 3000 DR Rotterdam, The Netherlands
}

Correspondence should be addressed to J A Visser; Email: j.visser@erasmusmc.nl

\begin{abstract}
Anti-Müllerian hormone (AMH) is a member of the transforming growth factor $\beta$ family of growth and differentiation factors. In the ovary, AMH has an inhibitory effect on primordial follicle recruitment as well as on the responsiveness of growing follicles to follicle-stimulating hormone (FSH). The ovary-specific expression pattern in granulosa cells of growing nonselected follicles makes AMH an ideal marker for the size of the ovarian follicle pool. This review summarizes recent findings concerning $\mathrm{AMH}$ and its role as a marker for the quantitative aspect of ovarian reserve as well as ovarian dysfunction.

Reproduction (2006) 131 1-9
\end{abstract}

\section{Introduction}

The ovarian reserve, constituted by the size of the ovarian follicle pool and the quality of the oocytes therein, declines with increasing age, resulting in the decrease of a woman's reproductive function (te Velde et al. 1998a). The size of the follicle pool is established at an early point in life. During fetal life, germ cells populate the ovary and become surrounded by somatic cells, forming the so-called primordial follicles. At birth, about 1 million oocytes are present. This number decreases during childhood, resulting in a primordial follicle pool of 300000-500000 follicles at menarche (Faddy et al. 1992). Throughout life, follicles leave the primordial follicle pool to enter the growing pool. The majority of these growing follicles will be lost as a result of atresia, unless they are rescued by follicle-stimulating hormone (FSH). This rescue by FSH starts after puberty when the pituitary-gonadal endocrine axis has been activated. Among the cohort of rescued follicles, only one follicle is selected to become the dominant follicle, which will ovulate under the influence of luteinizing hormone (LH) (McGee \& Hsueh 2000). This process continues throughout life until the primordial follicle pool is exhausted and, as a consequence, growing follicles are no longer present in the ovary, resulting in menopause. This classical view of a finite primordial follicle pool has been challenged recently by Johnson et al. (2004, 2005), who showed that germline stem cells can repopulate a germ cell-depleted postnatal ovary and renew the primordial follicle pool. However, it remains unknown to what extent this process delays the onset of menopause.
In the years preceding menopause, fertility already decreases and the menstrual cycle becomes irregular. This menopausal transition period precedes menopause by a fixed time interval (den Tonkelaar et al. 1998, te Velde et al. 1998b, te Velde \& Pearson 2002). In the Western world, menopause is reached at a median age of 51 years. However, there is considerable individual variation in the age of menopause and, subsequently, also in the age of subfertility (te Velde et al. 1998b, te Velde \& Pearson 2002). Hence, chronological age is a poor indicator of reproductive aging, and thus of the ovarian reserve.

To assess an individual's ovarian reserve, early follicular phase serum levels of $\mathrm{FSH}$, inhibin $\mathrm{B}$ and estradiol $\left(\mathrm{E}_{2}\right)$ have been measured. Inhibin $B$ and $E_{2}$ are produced by early antral follicles in response to $\mathrm{FSH}$, and contribute to the classical feedback loop of the pituitary-gonadal axis to suppress FSH secretion. With the decline of the follicle pool, serum levels of inhibin $B$ and $E_{2}$ decrease and subsequently serum FSH levels rise (Burger et al. 1995). Because these factors are part of a feedback system, their serum levels are not independent of each other. Furthermore, changes in serum levels of $\mathrm{FSH}$, inhibin $\mathrm{B}$ and $\mathrm{E}_{2}$ occur relatively late in the reproductive aging process (Burger et al. 1999). So far, assessment of the number of antral follicles by ultrasonography, the antral follicle count (AFC), best predicts the quantitative aspect of ovarian reserve (Scheffer et al. 2003). However, measurement of the AFC requires an additional transvaginal ultrasound examination during the early follicular phase. Therefore, a serum marker that reflects the number of follicles that have made the transition from the primordial pool into the growing follicle pool, and that is not controlled by gonadotropins, would benefit both patients and clinicians. 
In recent years, accumulated data indicate that anti-Müllerian hormone $(\mathrm{AMH})$ may fulfill this role.

\section{Anti-Müllerian hormone (AMH)}

AMH, also known as Müllerian inhibiting substance (MIS), has been mainly studied for its regulatory role in male sex differentiation. AMH, produced by the Sertoli cells of the fetal testis, induces the regression of the Müllerian ducts, the anlagen of the female reproductive tract (Josso et al. 1993, Lee \& Donahoe 1993). However, after birth, this sexdimorphic expression pattern is lost and $\mathrm{AMH}$ is also expressed in granulosa cells of growing follicles in the ovary.

Detailed studies in rodents have shown that $\mathrm{AMH}$ expression starts in the columnar granulosa cells of primary follicles immediately after differentiation from the flattened pregranulosa cells of primordial follicles. Expression is highest in granulosa cells of preantral and small antral follicles, and gradually diminishes in the subsequent stages of follicle development. $\mathrm{AMH}$ is no longer expressed during the FSHdependent final stages of follicle growth (Fig. 1). In addition, $\mathrm{AMH}$ expression disappears when follicles become atretic. The level of expression in follicles of the same class does not seem to change during the estrous cycle in rat, although some heterogeneity was observed in $\mathrm{AMH}$ expression in preantral and small antral follicles at estrous and diestrous (review by Durlinger et al. 2002a).

Interestingly, two major regulatory steps of folliculogenesis, initial follicle recruitment and cyclic selection for dominance (McGee \& Hsueh 2000), flank this window of expression. Analysis of the follicle dynamics in $\mathrm{AMH}$ null mice provided more insight into the intraovarian role of $\mathrm{AMH}$ and revealed that $\mathrm{AMH}$ specifically affects these two regulatory steps. Ovaries of 4-month-old $\mathrm{AMH}$ null mice contained almost threefold more small nonatretic growing follicles than their wild-type littermates, accompanied by a decrease in the number of primordial follicles (Durlinger et al. 1999). This increased recruitment had already started before the initiation of the estrous cycle, since a higher number of growing follicles was already evident in $\mathrm{AMH}$ null mice at day 25 . These results indicate that, in the absence of $\mathrm{AMH}$, primordial follicles are recruited at a faster rate. Consequently, the primordial follicle pool is prematurely exhausted and estrous cycling stops at an earlier age in AMH null mice (Durlinger et al. 1999). In vitro culture of neonatal ovaries in the presence of $\mathrm{AMH}$ confirmed the inhibitory effect of $\mathrm{AMH}$ on primordial follicle recruitment (Durlinger et al. 2002b). Based on the low $\mathrm{FSH}$ levels measured in $\mathrm{AMH}$ null mice in the presence of an increased number of growing follicles, it was hypothesized that, in the absence of $\mathrm{AMH}$, follicles are more sensitive to $\mathrm{FSH}$. Indeed, $\mathrm{AMH}$ inhibited FSH-dependent follicle growth of cultured mouse preantral follicles (Durlinger et al. 2001). Similarly, in granulosa cell cultures, $\mathrm{AMH}$ attenuates the $\mathrm{FSH}$-dependent increase in aromatase activity and $\mathrm{LH}$ receptor expression (di Clemente et al. 1994). Furthermore, an in vivo study in which FSH levels were modulated showed that in the presence of both low and high serum FSH concentrations more growing follicles are found in $\mathrm{AMH}$ null mice than in wild-type mice (Durlinger et al. 2001). This inhibitory effect of $\mathrm{AMH}$ on $\mathrm{FSH}$ sensitivity of follicles could play a role in the process of selection. It is thought that each follicle exerts its own threshold $\mathrm{FSH}$ concentration that has to be exceeded to allow selection. A role for $\mathrm{AMH}$ in this process is indirectly supported by the differential expression level of $\mathrm{AMH}$ in nonatretic, large preantral and small antral follicles in the rat ovary (Baarends et al. 1995). A low expression of $\mathrm{AMH}$ within the follicle would diminish the threshold level for FSH, allowing these follicles to continue growth and to ovulate in the next estrous cycle.

Although they are mostly based on rodent studies, these results also appear to apply to the human ovary. In women, $\mathrm{AMH}$ expression can first be observed in granulosa cells of primary follicles, and expression is strongest in preantral and small antral follicles $(\leq 4 \mathrm{~mm})$. $\mathrm{AMH}$ expression disappears in follicles of increasing size and is almost lost in follicles larger than $8 \mathrm{~mm}$, where only very weak staining remains, restricted to the granulosa cells of the cumulus (Weenen et al. 2004). This expression pattern suggests that, also in man, $\mathrm{AMH}$ may play a role in initial recruitment and in the selection of the dominant follicle
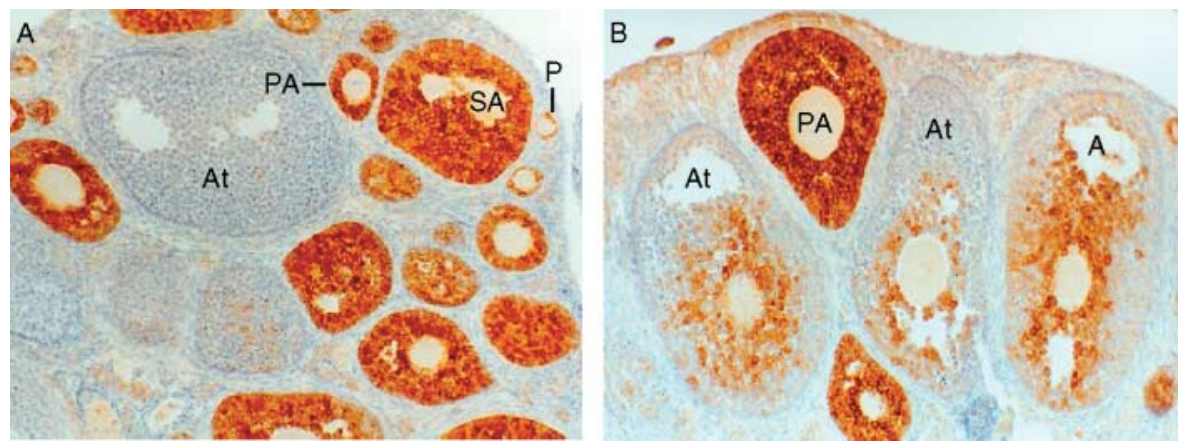

Figure $1 \mathrm{AMH}$ expression in mouse ovaries. (A) AMH is expressed in granulosa cells of primary (P), preantral (PA) and small antral (SA) follicles. (B) AMH expression disappears in antral (A) and atretic (At) follicles. Expression is lost last in the granulosa cells surrounding the oocytes. AMH expression was detected using a monoclonal antibody that recognises rat, mouse and human AMH. Magnification $\times 200$. 
(Fig. 2). The possible mechanisms of action of $\mathrm{AMH}$ are reviewed elsewhere (Durlinger et al. 2002a, Visser 2003).

\section{$\mathrm{AMH}$ as a marker for ovarian aging}

The specific expression pattern of $\mathrm{AMH}$ in growing nonselected follicles has prompted us and others to investigate whether serum AMH levels are indicative for the size of the growing follicle pool. As discussed above, the quantitative aspect of ovarian aging is reflected by a decline in the size of the primordial follicle pool. Direct measurement of the primordial follicle pool is impossible. However, the number of primordial follicles is indirectly reflected by the number of growing follicles (Scheffer et al. 1999). Hence, a factor primarily secreted by growing follicles will reflect the size of the primordial follicle pool. Since AMH is expressed by growing follicles up to selection (Durlinger et al. 2002a), and can be detected in serum (Hudson et al. 1990, Lee et al. 1996), it is a promising candidate.

In young normal ovulatory women, early follicular phase hormone measurements at 3-year intervals revealed that serum AMH levels decline significantly whereas serum levels of $\mathrm{FSH}$ and inhibin $\mathrm{B}$ and the number of antral follicles do not change during this interval (de Vet et al. 2002). Stratification for age revealed that both serum $\mathrm{AMH}$ levels and numbers of antral follicles decline with age (Fig. 3A). Importantly, a strong correlation of serum AMH levels with AFC was observed (Fig. 3B). This positive correlation was later confirmed by Fanchin et al. (2003b), who showed a stronger correlation between serum $\mathrm{AMH}$ levels and follicle count than between $\mathrm{AMH}$ and serum levels of inhibin $\mathrm{B}, \mathrm{FSH}$, and $\mathrm{E}_{2}$ on cycle day 3 .

The results of de Vet et al. (2002) also suggest that changes in serum AMH levels occur relatively early in the sequence of events associated with ovarian aging. Substantially elevated serum levels of FSH are not found until cycles have already become irregular (Burger et al. 1999). Therefore, a marker that already shows a considerable change when cyclicity is still normal would better identify women with declining fertility. Indeed, in studies by van

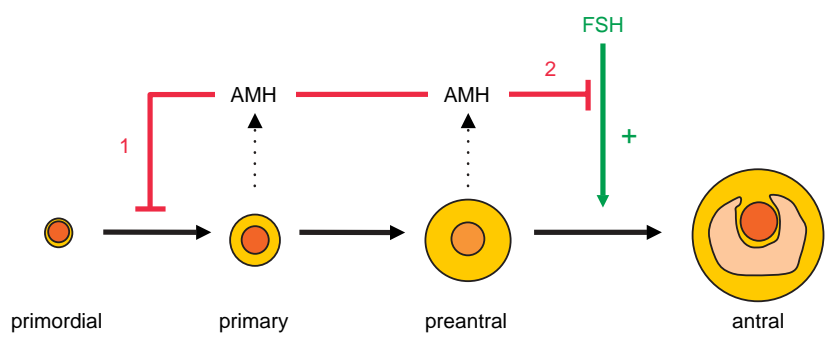

Figure 2 Model of AMH action in the ovary. Progressing stages of folliculogenesis are depicted. AMH is produced by the small growing (primary and preantral) follicles in the postnatal ovary and has two sites of action. It inhibits initial follicle recruitment (1) and inhibits FSH-dependent growth and selection of preantral and small antral follicles (2).
Rooij et al. (2004, 2005), in which several markers of aging were measured in normal women at 4-year intervals, serum levels of $\mathrm{AMH}$ gave the highest accuracy $\left(\mathrm{ROC}_{\mathrm{AUC}} 0.87\right)$ to predict occurrence of menopausal transition within 4 years. When serum inhibin B levels and age were included in a multivariate model, the ROC $_{A \cup C}$ improved to 0.92. Furthermore, compared to other ovarian reserve markers, only serum $\mathrm{AMH}$ level showed a mean longitudinal decline over time. Taken together, these data strongly suggest that serum levels of $\mathrm{AMH}$ can be used as a marker of ovarian aging.

The usefulness of serum AMH levels as a measure of the ovarian reserve was recently shown in young women after treatment for childhood cancer. Chemotherapy and radiotherapy treatment have adverse effects on the ovary in particular, resulting in loss of primordial follicles. Indeed, in cancer survivors, the partial loss of the ovarian reserve is reflected by increased $\mathrm{FSH}$ levels and decreased ovarian volume. Unexpectedly, the number of small antral follicles is unchanged (Bath et al. 2003), a finding that may reflect the low accuracy and observer dependency of AFC measurements. Nevertheless, serum AMH levels were decreased in these patients, supporting the use of serum AMH levels as an early predictor of the ovarian reserve.

\section{AMH as a marker of ovarian responsiveness}

$\mathrm{AMH}$ 's role as a peripheral signal of the size of the growing follicle pool may have important clinical benefits. In women undergoing treatment for infertility, ovarian aging is characterized by decreased ovarian responsiveness to exogenous gonadotropin administration and poor pregnancy outcome. On the one hand, correct identification of poor responders by assessment of their ovarian reserve before entering an in vitro fertilization (IVF) program is important. On the other hand, assessment of the ovarian reserve may also benefit patients that would generally be excluded from IVF programs because of advanced age.

Several studies have shown that $\mathrm{AMH}$ is an excellent marker to determine ovarian responsiveness also in an IVF program. Hormone measurements in the early follicular phase (day 3 of spontaneous cycle), retrospectively or in a group of unselected patients, revealed that $\mathrm{AMH}$ levels are lower in patients with poor ovarian response than in women with normal response (Seifer et al. 2002, van Rooij et al. 2002), ovarian responsiveness being defined as the number of oocytes retrieved, or as cancellation due to impaired or absent follicular growth. In agreement with the studies described above, AMH serum levels were shown to be highly correlated with the number of antral follicles before treatment and number of oocytes retrieved upon ovarian stimulation (van Rooij et al. 2002). Logistic regression analysis for prediction of poor response showed that serum $\mathrm{AMH}$ levels had a better predictive value than serum levels of $\mathrm{FSH}$, inhibin $\mathrm{B}$ and $\mathrm{E}_{2}$, and that the 

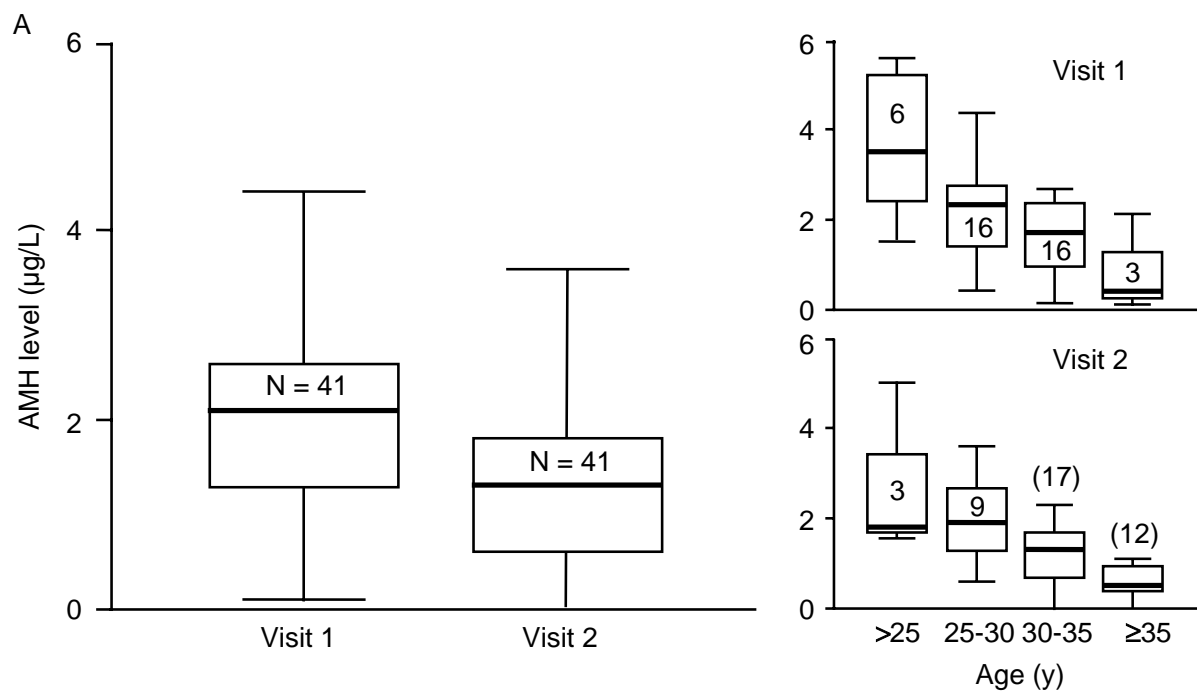

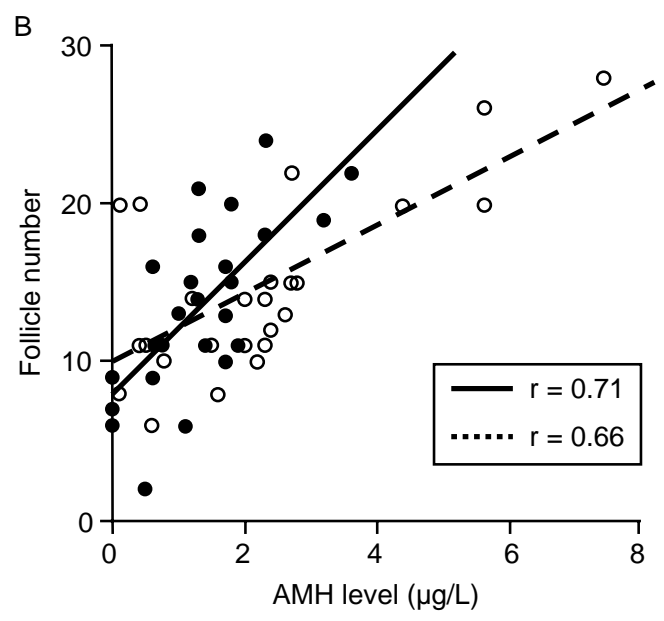

Figure 3 Serum AMH levels in normoovulatory women. (A) Box and whiskers plots show declining AMH levels with increasing age. $\mathrm{AMH}$ levels were measured at two time points with a $2.6 \pm 1.7$-year interval. (B) AMH levels positively correlate with numbers of antral follicles at visit 1 (closed circles, solid line) and visit 2 (open circles, dotted line). Reproduced from de Vet et al. (2002), with permission from American Society for Reproductive Medicine.

Table 1 Logistic regression for prediction of poor response after ovarian hyperstimulation.

\begin{tabular}{lccc}
\hline Univariate analysis & Odds ratio $\mathbf{( 9 5} \% \mathbf{~ C l})$ & P & ROC $_{\text {AUC }}$ \\
\hline AFC (per follicle) & $0.70(0.61-0.81)$ & $<0.001$ & 0.86 \\
AMH (per 0.1 $\mu \mathrm{g} / \mathrm{l})$ & $0.82(0.75-0.90)$ & $<0.001$ & 0.85 \\
FSH (per IU/l) & $1.41(1.22-1.63)$ & $<0.001$ & 0.83 \\
Inhibin B (per ng/l) & $0.98(0.97-0.99)$ & $<0.001$ & 0.76 \\
Age (per year) & $1.07(0.99-1.16)$ & $\mathrm{NS}$ & 0.60 \\
$\mathrm{E}_{2}$ (per pmol/l) & $1.003(1.000-1.006)$ & $\mathrm{NS}$ & 0.52 \\
\hline
\end{tabular}

Multivariate analysis

OR $(95 \% \mathrm{CI})$

$\mathrm{ROC}_{\mathrm{AUC}}$ (final model)

All variables

AFC (per follicle) and

Inhibin B (per pg/ml) and

FSH (per IU/I)

AFC excluded from analysis

$\mathrm{AMH}$ (per $0.1 \mu \mathrm{g} / \mathrm{l}$ ) and

Inhibin B (per pg/ml) and

$\begin{array}{ll}0.77(0.65-0.90) & 0.001 \\ 0.98(0.97-0.99) & 0.006 \\ 1.27(1.07-1.50) & 0.006 \\ 0.90(0.82-0.98) & 0.018 \\ 0.98(0.97-0.99) & 0.005 \\ 1.26(1.07-1.50) & 0.006\end{array}$

0.92

0.018

0.006

0.90

Data taken from van Rooij et al. (2002), (c) European Society of Human Reproduction and Embryology. Reproduced by permission of Oxford University Press/Human Reproduction. 
predictive values for $\mathrm{AMH}$ and $\mathrm{AFC}$ were almost identical (ROC $_{\text {AUC }} 0.85$ vs 0.86) (Table 1). Inclusion of FSH and inhibin $\mathrm{B}$ together with $\mathrm{AMH}$ in a multivariate model improved this predictive value to 0.90 (van Rooij et al. 2002) (Table 1). Similarly, cycle day-5 AMH levels are a better marker of ovarian responsiveness than inhibin B levels (Muttukrishna et al. 2004). Measurement of serum AMH levels has several advantages over other serum markers such as $\mathrm{FSH}$, inhibin $\mathrm{B}$ and $\mathrm{E}_{2}$. To achieve a reliable predictive outcome, one single hormone measurement for AMH seems sufficient (Fanchin et al. 2005a). Furthermore, in contrast to $\mathrm{FSH}$, inhibin $\mathrm{B}$ and $\mathrm{E}_{2}, \mathrm{AMH}$ levels remain relatively constant during the follicular phase and entire menstrual cycle (Cook et al. 2000, La Marca et al. 2004a, and our own unpublished results $(\mathrm{F} \mathrm{H} \mathrm{J}, \mathrm{J} L, A \mathrm{~T}$ and Dr F Broekmans), consistent with the continuous, noncyclic growth of small follicles.

The absence of regulation of $\mathrm{AMH}$ by gonadotropins was shown in both rodents and man. Heterozygous $\mathrm{AMH}$ null mice present with an ovarian phenotype between that of wild-type and homozygous AMH null mice (Durlinger et al. 1999), suggesting that $\mathrm{AMH}$ acts as a paracrine rather than a systemic factor, and thus is not part of a negative feedback loop with involvement of gonadotropins. In agreement, treatment of IVF patients with a single, high dose of gonadotropin-releasing hormone $(\mathrm{GnRH})$ agonist, resulting in a rise of endogenous $\mathrm{FSH}$ and $\mathrm{LH}$, does not affect $\mathrm{AMH}$ serum levels (van Rooij et al. 2002). Similarly, in conditions where FSH levels are suppressed, such as pregnancy, AMH levels remain constant (La Marca et al. 2005). Thus, AMH is not influenced by the gonadotropic status and reflects only the follicle population. The latter conclusion was confirmed in a more detailed study by Fanchin et al. (2003a), who treated women with FSH and human chorionic gonadotropin (hCG) after complete pituitary desensitization with a GnRH agonist. In a normal menstrual cycle, the early antral follicle pool remains intact throughout the follicular phase. However, upon ovarian hyperstimulation, all small antral follicles are stimulated to the preovulatory stage, thus providing a model to determine the relationship between AMH levels and follicle dynamics. Serum AMH levels, determined at three day during $\mathrm{FSH}$ treatment and at the day of hCG administration, decline significantly at each consecutive measurement (Fanchin et al. 2003a), reflecting the reduction in number of small antral follicles. A decline in serum AMH was also observed after FSH administration immediately following a spontaneous cycle (La Marca et al. 2004a). Moreover, on day 5 of gonadotropin therapy, levels of serum AMH and estradiol constitute an even better prediction of the ovarian response than cycle day $3 \mathrm{AMH}$ levels (Penarrubia et al. 2005). However, from a clinical point of view, poor responders should be identified before treatment; therefore, it is more useful to determine serum $\mathrm{AMH}$ levels during a spontaneous cycle.
Throughout the controlled ovarian hyperstimulation protocol, serum $\mathrm{AMH}$ levels correlated well with the decrease in number of small antral follicles $(\leq 12 \mathrm{~mm}$ ) (Fanchin et al. 2003a), reflecting the complete conversion of small antral follicles into large antral follicles in response to $\mathrm{FSH}$ stimulation. Indeed, no correlation with the number of growing follicles $(>12 \mathrm{~mm}$ ) was observed (Fanchin et al. 2003a), in line with the low expression of $\mathrm{AMH}$ in these follicles (Weenen et al. 2004). In the days following hCG treatment, $\mathrm{AMH}$ serum levels initially declined, possibly as a result of the luteinization of granulosa cells upon hCG treatment that also causes a decline in $E_{2}$ levels. During the midluteal phase, $A M H$ serum levels slightly increased, probably as a result of the presence of newly developed, small antral follicles (Fanchin et al. 2005b). Thus, these changes in serum AMH levels seem to reflect follicle dynamics rather than regulation by gonadotropins.

All combined these studies strongly support a role of serum AMH level as a marker for ovarian responsiveness. However, the application of $\mathrm{AMH}$ to predict ongoing pregnancy seems limited, although day 3 serum AMH levels are higher in patients that become pregnant after IVF treatment than in those who do not (Hazout et al. 2004). However, data on pregnancy outcome were not stratified for the number of retrieved oocytes, which also in this study showed a positive correlation with AMH levels. Therefore, it is likely that the quantitative aspect of $\mathrm{AMH}$ as a marker of the ovarian reserve has contributed predominantly to the association with pregnancy outcome. Indeed, other studies did not observe a predictive value of $\mathrm{AMH}$ serum levels for ongoing pregnancy after IVF treatment (van Rooij et al. 2002, Penarrubia et al. 2005).

\section{AMH as a marker for ovarian pathophysiology}

The results of the studies described above indicate that serum $\mathrm{AMH}$ level can be used as a marker for the number of growing follicles. Besides being a marker for a diminishing follicle pool, serum AMH level can also serve as a marker in ovarian pathophysiology, such as polycystic ovary syndrome (PCOS), in which the antral follicle pool is enlarged. PCOS is one of the most common endocrine disorders in women of reproductive age (Franks 1995). It is characterized by anovulation manifested as oligo- or amenorrhea, elevated levels of circulating androgens, and polycystic ovaries as visualized by ultrasound. The diagnosis is based on the presence of at least two of the described characteristics, as defined by the Rotterdam Consensus (2004). PCOS encompasses a broad spectrum of clinical and biochemical characteristics, and, although the mechanisms leading to PCOS are still poorly understood, the common denominator is a disturbance in the selection of the dominant follicle resulting in anovulation. The defective selection mechanism results in an accumulation of small antral follicles, which contribute 
significantly to the production of $\mathrm{AMH}$. As discussed above, studies in mice showed that AMH lowers the sensitivity of follicles to FSH (Durlinger et al. 2001), possibly contributing to deranged follicle selection. It has been suggested that aromatase activity in PCOS patients might be decreased because follicles from PCOS women do not produce large amounts of $E_{2}$ (Agarwal et al. 1996). $\mathrm{AMH}$ also inhibits aromatase activity, as discussed above, suggesting that $\mathrm{AMH}$ contributes to the severity of PCOS.

Initial studies showed that follicular fluid and serum of PCOS women contained increased $\mathrm{AMH}$ levels (Fallat et al. 1997, Cook et al. 2002). In agreement with previous results obtained in normal cycling women, also in PCOS women serum AMH levels were correlated with antral follicle number. The two- to threefold increase in the number of growing follicles is reflected by a two- to threefold increase in serum AMH level (Pigny et al. 2003, Laven et al. 2004) (Fig. 4). In PCOS, the follicular excess is mainly caused by an increase of small antral follicles upto $2-5 \mathrm{~mm}$ in size (Hughesdon 1982, Jonard et al. 2003). Interestingly, in follicles beyond this stage, $\mathrm{AMH}$ expression diminishes (Weenen et al. 2004). Therefore, it is not surprising that serum AMH levels positively correlate with the number of 2-5 mm, but not 6-9 mm, follicles in PCOS women (Pigny et al. 2003). The finding that $\mathrm{AMH}$ levels are also increased in the follicular fluid of PCOS women (Fallat et al. 1997) suggests that the increase in serum $\mathrm{AMH}$ levels is not only due to an increase in the number of growing follicles, but may also result from increased $\mathrm{AMH}$ production per follicle. So far little is known about the factors that regulate $\mathrm{AMH}$ expression in the ovary.

Categorization of anovulatory women into groups with or without polycystic ovaries (PCO), by number of antral follicles ( $\geq 12$ follicles per ovary measuring $2-9 \mathrm{~mm}$ ) or

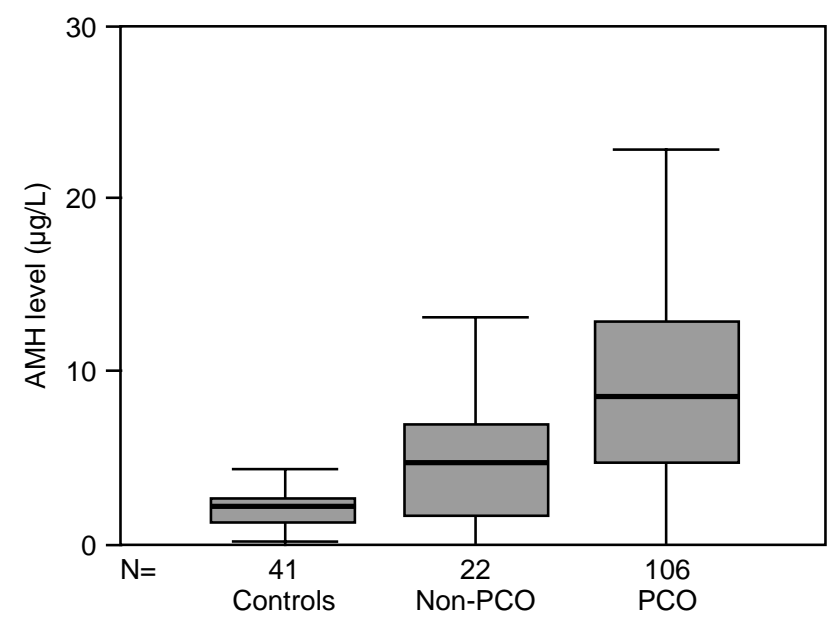

Figure 4 Serum AMH levels are increased in normogonadotropic anovulatory infertile women. Box and whisker plots show $\mathrm{AMH}$ levels in infertile women with PCO and those without (non-PCO) compared with control women. Reproduced from Laven et al. (2004) (C)2004, Endocrine Society). ovarian volume $(>10 \mathrm{ml})$, revealed that serum $\mathrm{AMH}$ levels were significantly higher in the PCO group than in nonPCO patients (Laven et al. 2004). Nevertheless, serum levels in non-PCO women were still significantly elevated compared to those in control women (Fig. 4). This suggests that the pool of smaller follicles, which is not detected on ultrasound, may be increased and contributes significantly to serum AMH levels in anovulatory women. In a study by Eldar-Geva et al. (2005), categorization of PCOS women by presence or absence of hyperandrogenism showed that $\mathrm{AMH}$ levels were significantly different between groups. Both groups had increased $\mathrm{AMH}$ levels compared to control women, but levels in women with PCO and hyperandrogenism were even further elevated. Interestingly, the numbers of small antral follicles did not differ between the two PCO groups, and multiple regression analysis showed that follicle number and testosterone levels independently correlated with $\mathrm{AMH}$ serum levels (Eldar-Geva et al. 2005). These results suggest that the nonvisible pool of follicles may be further increased in the presence of increased androgen levels. Indeed, in the rhesus monkey, androgens stimulate the initiation of primordial follicle growth (Vendola et al. 1999). In addition, androgens stimulate the proliferation of granulosa and theca cells of growing follicles in rhesus monkeys (Vendola et al. 1998). It is possible that under these conditions follicles may produce more $A M H$. Since $A M H$ inhibits aromatase activity, local androgen concentrations may be increased, possibly resulting in a positive feedback mechanism between $\mathrm{AMH}$ and androgens. However, the mechanism behind the positive association between androgens and $\mathrm{AMH}$ in PCOS women requires further studies, in particular, since in males during puberty an inverse relationship between $\mathrm{AMH}$ and testosterone levels was found (Rey et al. 1993). In this respect, it would be interesting to analyze the expression level and pattern of $\mathrm{AMH}$ by immunohistochemical analysis in polycystic ovaries of women with or without hyperandrogenism.

In PCOS women, levels of serum $\mathrm{AMH}$ are also correlated with other clinical features, such as cycle duration, mean ovarian volume, testosterone and androstenedione levels, and free androgen index, whereas no correlations with inhibin $B$ and $E_{2}$ levels were observed (Pigny et al. 2003, Laven et al. 2004).

A substantial proportion of PCOS women are obese and exhibit insulin resistance and compensatory hyperinsulinemia (Dunaif 1997). The increased insulin levels in some PCOS women can, in part, account for the hyperandrogenism, because insulin acts synergistically with $\mathrm{LH}$ to enhance androgen production by theca cells (Franks et al. 1999). However, serum AMH levels do not seem to correlate with BMI and insulin levels (Pigny et al. 2003, Laven et al. 2004, Fleming et al. 2005). In contrast, in a small study, La Marca et al. (2004b) observed a positive correlation between serum AMH levels and the HOMA index, an insulin resistance index calculated from fasting insulin and fasting glucose levels. 
Improvement of insulin levels by insulin-lowering drugs, such as metformin and thiazolidinediones, which also indirectly affect androgen production, have been shown to be beneficial in PCOS women (Franks et al. 1999). In a study of obese PCOS women, metformin treatment suppressed androstenedione levels and ovulation rate (Fleming et al. 2005), although androgen levels were still above the upper limit of the normal range. Metformin administration also resulted in a small but significant reduction of serum AMH levels after 8 months of treatment, whereas the follicle number did not change significantly (Fleming et al. 2005). In a smaller study, metformin treatment for 6 months also decreased serum AMH levels only slightly (Piltonen et al. 2005), and levels remained strongly elevated compared to controls. Although AMH and androgen levels are positively correlated in PCOS women, the decrease in AMH levels may be secondary to the decrease in androgens upon metformin treatment. Furthermore, since the number of follicles is not likely to change in a short period of time, more detailed studies with longer follow-up are required to determine the longterm effect of insulin-lowering agents on AMH levels.

As in cycling women, AMH levels decline with increasing age in PCOS. However, the decrease in serum levels is significantly different from that in controls (Laven et al. 2004). A follow-up study investigated this phenomenon in more detail by measuring serum AMH levels in control and PCOS women on two occasions with a median time interval of 2.6 years. Although AMH levels had declined over time in both groups, the decline was less pronounced in PCOS women (Mulders et al. 2004). These results were confirmed by Piltonen et al. (2005), who showed that, in contrast to older control women with low to undetectable AMH levels, women with PCOS of the same age still had high AMH levels. This suggests that the ovarian aging process in PCOS women may have been slowed down, possibly due to suppressed primordial follicle outgrowth by the high levels of AMH observed in these women. However, it has also been suggested that exhaustion of the primordial follicle pool occurs later in PCOS women because their intrinsic primordial follicle pool may be increased (Webber et al. 2003). Data regarding the menopausal age in PCOS women are scarce. However, smaller studies seem to indicate that women with PCOS reach menopause at an older age (Dahlgren et al. 1992).

\section{Conclusions and future directions}

The studies described here indicate that serum $\mathrm{AMH}$ levels decrease with age in premenopausal women. In addition, serum levels of AMH correlate strongly with the number of antral follicles, suggesting that $\mathrm{AMH}$ levels by extension reflect the size of the primordial follicle pool. Assessment of the ovarian reserve is particularly important in the IVF clinic, where AMH may be useful as a predictor of poor response. Since a considerable proportion of subfertility is due to postponement of childbearing, measurement of $\mathrm{AMH}$ levels to assess the ovarian reserve may also be of interest in women in general. Assessment of the ovarian reserve, at least of the size of the ovarian follicle pool, may provide insight into the number of fertile years a woman has left. However, in order to determine whether serum AMH level has prognostic value, additional prospective studies in a normal population are necessary to provide definite proof for this concept.

The positive correlation between serum AMH levels and number of antral follicles is also observed in women with PCOS. The elevated levels of AMH in these women strongly suggest that serum AMH levels may also be used in the diagnosis of PCOS. The difference in serum levels of $\mathrm{AMH}$ between subgroups of PCOS women suggests that $\mathrm{AMH}$ might also be used to establish a subclassification of this heterogeneous syndrome. However, more studies, preferably prospective, with thoroughly analyzed patient cohorts are necessary to define cutoff values. In addition, studies are necessary to determine whether serum AMH levels are also indicative of improved ovarian function upon treatment of PCOS women.

In conclusion, recent studies have validated the use of serum $\mathrm{AMH}$ levels as a marker for the quantitative aspect of ovarian reserve. Because AMH levels are strongly correlated with the size of the follicle pool, and because of the lack of cycle variations, serum levels of AMH are a good candidate for inclusion in standard diagnostic procedures to assess other ovarian dysfunctions, such as premature ovarian failure. Knowledge of the serum AMH levels in such conditions might provide more insight into the possible cause or effect of altered AMH levels. Genetic studies of well-defined population cohorts would also provide more knowledge about the role of $\mathrm{AMH}$ in ovarian physiology.

\section{Acknowledgements}

The authors declare that there is no conflict of interest that would prejudice the impartiality of this scientific work.

\section{References}

Agarwal SK, Judd HL \& Magoffin DA 1996 A mechanism for the suppression of estrogen production in polycystic ovary syndrome. Journal of Clinical Endocrinology and Metabolism 81 3686-3691.

Baarends WM, Uilenbroek JT, Kramer P, Hoogerbrugge JW, van Leeuwen EC, Themmen APN \& Grootegoed JA 1995 Anti-mullerian hormone and anti-mullerian hormone type II receptor messenger ribonucleic acid expression in rat ovaries during postnatal development, the estrous cycle, and gonadotropin-induced follicle growth. Endocrinology 136 4951-4962.

Bath LE, Wallace WH, Shaw MP, Fitzpatrick C \& Anderson RA 2003 Depletion of ovarian reserve in young women after treatment for cancer in childhood: detection by anti-Mullerian hormone, inhibin B and ovarian ultrasound. Human Reproduction 18 2368-2374.

Burger HG, Dudley EC, Hopper JL, Shelley JM, Green A, Smith A, Dennerstein L \& Morse C 1995 The endocrinology of the menopausal transition: a cross-sectional study of a population-based 
sample. Journal of Clinical Endocrinology and Metabolism 80 3537-3545.

Burger HG, Dudley EC, Hopper JL, Groome N, Guthrie JR, Green A \& Dennerstein L 1999 Prospectively measured levels of serum follicle-stimulating hormone, estradiol, and the dimeric inhibins during the menopausal transition in a population-based cohort of women. Journal of Clinical Endocrinology and Metabolism 84 4025-4030.

Cook CL, Siow Y, Taylor S \& Fallat ME 2000 Serum mullerian-inhibiting substance levels during normal menstrual cycles. Fertility and Sterility 73 859-861.

Cook CL, Siow Y, Brenner AG \& Fallat ME 2002 Relationship between serum mullerian-inhibiting substance and other reproductive hormones in untreated women with polycystic ovary syndrome and normal women. Fertility and Sterility 77 141-146.

Dahlgren E, Johansson S, Lindstedt G, Knutsson F, Oden A, Janson PO, Mattson LA, Crona N \& Lundberg PA 1992 Women with polycystic ovary syndrome wedge resected in 1956 to 1965: a long-term follow-up focusing on natural history and circulating hormones. Fertility and Sterility 57 505-513.

den Tonkelaar I, te Velde ER \& Looman CW 1998 Menstrual cycle length preceding menopause in relation to age at menopause. Maturitas 29 115-123.

de Vet A, Laven JS, de Jong FH, Themmen APN \& Fauser BC 2002 Antimullerian hormone serum levels: a putative marker for ovarian aging. Fertility and Sterility 77 357-362.

di Clemente N, Goxe B, Rémy JJ, Cate RL, Josso N, Vigier B \& Salesse R 1994 Inhibitory effect of AMH upon aromatase activity and $\mathrm{LH}$ receptors of granulosa cells of rat and porcine immature ovaries. Endocrine $2553-558$.

Dunaif A 1997 Insulin resistance and the polycystic ovary syndrome: mechanism and implications for pathogenesis. Endocrine Reviews 18 774-800.

Durlinger ALL, Kramer P, Karels B, de Jong FH, Uilenbroek JT, Grootegoed JA \& Themmen APN 1999 Control of primordial follicle recruitment by anti-Mullerian hormone in the mouse ovary. Endocrinology 140 5789-5796.

Durlinger ALL, Gruijters MJ, Kramer P, Karels B, Kumar TR, Matzuk MM, Rose UM, de Jong FH, Uilenbroek JT, Grootegoed JA \& Themmen APN 2001 Anti-Mullerian hormone attenuates the effects of FSH on follicle development in the mouse ovary. Endocrinology $1424891-4899$.

Durlinger ALL, Visser JA \& Themmen APN 2002a Regulation of ovarian function: the role of anti-Mullerian hormone. Reproduction 124 601-609.

Durlinger ALL, Gruijters MJ, Kramer P, Karels B, Ingraham HA, Nachtigal MW, Uilenbroek JT, Grootegoed JA \& Themmen APN $2002 b$ Anti-Mullerian hormone inhibits initiation of primordial follicle growth in the mouse ovary. Endocrinology 143 1076-1084.

Eldar-Geva T, Margalioth EJ, Gal $M$, Ben-Chetrit A, Algur N, Zylber-Haran E, Brooks B, Huerta M \& Spitz IM 2005 Serum anti-Mullerian hormone levels during controlled ovarian hyperstimulation in women with polycystic ovaries with and without hyperandrogenism. Human Reproduction 20 1814-1819.

Faddy MJ, Gosden RG, Gougeon A, Richardson SJ \& Nelson JF 1992 Accelerated disappearance of ovarian follicles in mid-life: implications for forecasting menopause. Human Reproduction 7 $1342-1346$.

Fallat ME, Siow Y, Marra M, Cook C \& Carrillo A 1997 Mullerianinhibiting substance in follicular fluid and serum: a comparison of patients with tubal factor infertility, polycystic ovary syndrome, and endometriosis. Fertility and Sterility 67 962-965.

Fanchin R, Schonauer LM, Righini C, Frydman N, Frydman R \& Taieb J 2003a Serum anti-Mullerian hormone dynamics during controlled ovarian hyperstimulation. Human Reproduction 18 328-332.

Fanchin R, Schonauer LM, Righini C, Guibourdenche J, Frydman R \& Taieb J 2003b Serum anti-Mullerian hormone is more strongly related to ovarian follicular status than serum inhibin B, estradiol, FSH and LH on day 3. Human Reproduction 18 323-327.
Fanchin R, Taieb J, Lozano DH, Ducot B, Frydman R \& Bouyer J 2005a High reproducibility of serum anti-Mullerian hormone measurements suggests a multi-staged follicular secretion and strengthens its role in the assessment of ovarian follicular status. Human Reproduction 20 923-927.

Fanchin R, Mendez Lozan DH, Louafi N, Achour-Frydman N, Frydman R \& Taieb J 2005b Dynamics of serum anti-Mullerian hormone levels during the luteal phase of controlled ovarian hyperstimulation. Human Reproduction 20 747-751.

Fleming R, Harborne L, MacLaughlin DT, Ling D, Norman J, Sattar N \& Seifer DB 2005 Metformin reduces serum mullerian-inhibiting substance levels in women with polycystic ovary syndrome after protracted treatment. Fertility and Sterility 83 130-136.

Franks S 1995 Polycystic ovary syndrome. New England Journal of Medicine 333 853-861.

Franks S, Gilling-Smith C, Watson H \& Willis D 1999 Insulin action in the normal and polycystic ovary. Journal of Clinical Endocrinology and Metabolism 28 361-378.

Hazout A, Bouchard P, Seifer DB, Aussage P, Junca AM \& Cohen-Bacrie $\mathbf{P}$ 2004 Serum antimullerian hormone/mullerian-inhibiting substance appears to be a more discriminatory marker of assisted reproductive technology outcome than follicle-stimulating hormone, inhibin B, or estradiol. Fertility and Sterility 82 1323-1329.

Hudson PL, Dougas I, Donahoe PK, Cate RL, Epstein J, Pepinsky RB \& MacLaughlin DT 1990 An immunoassay to detect human mullerian inhibiting substance in males and females during normal development. Journal of Clinical Endocrinology and Metabolism 70 16-22.

Hughesdon PE 1982 Morphology and morphogenesis of the SteinLeventhal ovary and of so-called 'hyperthecosis'. Obstetrical and Gynecological Survey 37 59-77.

Johnson J, Canning J, Kaneko T, Pru JK \& Tilly JL 2004 Germline stem cells and follicular renewal in the postnatal mammalian ovary. Nature 428 145-150.

Johnson J, Bagley J, Skaznik-Wikiel M, Lee HJ, Adams GB, Niikura Y, Tschudy KS, Tilly JC, Cortes ML, Forkert R, Spitzer T, lacomini J, Scadden DT \& Tilly JL 2005 Oocyte generation in adult mammalian ovaries by putative germ cells in bone marrow and peripheral blood. Cell 122 303-315.

Jonard S, Robert Y, Cortet-Rudelli C, Pigny P, Decanter C \& Dewailly D 2003 Ultrasound examination of polycystic ovaries: is it worth counting the follicles? Human Reproduction 18 598-603.

Josso N, Cate RL, Picard JY, Vigier B, di Clemente N, Wilson C, Imbeaud S, Pepinsky RB, Guerrier D, Boussin L, Legeai L \& Carré-Eusèbe D 1993 Anti-mullerian hormone: the Jost factor. Recent Progress in Hormone Research 48 1-59.

La Marca A, Malmusi S, Giulini S, Tamaro LF, Orvieto R, Levratti P \& Volpe A 2004aa Anti-Mullerian hormone plasma levels in spontaneous menstrual cycle and during treatment with FSH to induce ovulation. Human Reproduction 19 2738-2741.

La Marca A, Orvieto R, Giulini S, Jasonni VM, Volpe A \& De Leo V 2004bb Mullerian-inhibiting substance in women with polycystic ovary syndrome: relationship with hormonal and metabolic characteristics. Fertility and Sterility 82 970-972.

La Marca A, Giulini S, Orvieto R, De Leo V \& Volpe A 2005 AntiMullerian hormone concentrations in maternal serum during pregnancy. Human Reproduction 20 1569-1572.

Laven JS, Mulders AG, Visser JA, Themmen APN, De Jong FH \& Fauser BC 2004 Anti-Mullerian hormone serum concentrations in normoovulatory and anovulatory women of reproductive age. Journal of Clinical Endocrinology and Metabolism 89 318-323.

Lee MM \& Donahoe PK 1993 Mullerian inhibiting substance: a gonadal hormone with multiple functions. Endocrine Reviews 14 $152-164$.

Lee MM, Donahoe PK, Hasegawa T, Silverman B, Crist GB, Best S, Hasegawa Y, Noto RA, Schoenfeld D \& MacLaughlin DT 1996 Mullerian inhibiting substance in humans: normal levels from infancy to adulthood. Journal of Clinical Endocrinology and Metabolism 81 571-576. 
McGee EA \& Hsueh AJ 2000 Initial and cyclic recruitment of ovarian follicles. Endocrine Reviews 21 200-214.

Mulders AG, Laven JS, Eijkemans MJ, de Jong FH, Themmen APN \& Fauser BC 2004 Changes in anti-Mullerian hormone serum concentrations over time suggest delayed ovarian ageing in normogonadotrophic anovulatory infertility. Human Reproduction 19 2036-2042.

Muttukrishna S, Suharjono H, McGarrigle H \& Sathanandan M 2004 Inhibin B and anti-Mullerian hormone: markers of ovarian response in IVF/ICSI patients? BJOG 111 1248-1253.

Penarrubia J, Fabregues F, Manau D, Creus M, Casals G, Casamitjana R, Carmona F, Vanrell JA \& Balasch J 2005 Basal and stimulation day 5 anti-Mullerian hormone serum concentrations as predictors of ovarian response and pregnancy in assisted reproductive technology cycles stimulated with gonadotropin-releasing hormone agonistgonadotropin treatment. Human Reproduction 20 915-922.

Pigny P, Merlen E, Robert Y, Cortet-Rudelli C, Decanter C, Jonard S \& Dewailly D 2003 Elevated serum level of anti-mullerian hormone in patients with polycystic ovary syndrome: relationship to the ovarian follicle excess and to the follicular arrest. Journal of Clinical Endocrinology and Metabolism 88 5957-5962.

Piltonen T, Morin-Papunen L, Koivunen R, Perheentupa A, Ruokonen A \& Tapanainen JS 2005 Serum anti-Mullerian hormone levels remain high until late reproductive age and decrease during metformin therapy in women with polycystic ovary syndrome. Human Reproduction 20 1820-1826.

Rey R, Lordereau-Richard I, Carel JC, Barbet P, Cate RL, Roger M, Chaussain JL \& Josso N 1993 Anti-mullerian hormone and testosterone serum levels are inversely related during normal and precocious pubertal development. Journal of Clinical Endocrinology and Metabolism 77 1220-1226.

Rotterdam Consensus, 2004 Revised 2003 consensus on diagnostic criteria and long-term health risks related to polycystic ovary syndrome (PCOS). Human Reproduction 19 41-47.

Scheffer GJ, Broekmans FJ, Dorland M, Habbema JD, Looman CW \& te Velde ER 1999 Antral follicle counts by transvaginal ultrasonography are related to age in women with proven natural fertility. Fertility and Sterility 72 845-851.

Scheffer GJ, Broekmans FJ, Looman CW, Blankenstein M, Fauser BC, de Jong FH \& te Velde ER 2003 The number of antral follicles in normal women with proven fertility is the best reflection of reproductive age. Human Reproduction 18 700-706.

Seifer DB, MacLaughlin DT, Christian BP, Feng B \& Shelden RM 2002 Early follicular serum mullerian-inhibiting substance levels are associated with ovarian response during assisted reproductive technology cycles. Fertility and Sterility 77 468-471. te Velde ER \& Pearson PL 2002 The variability of female reproductive ageing. Human Reproduction Update 8 141-154.

te Velde ER, Scheffer GJ, Dorland M, Broekmans FJ \& Fauser BC 1998aa Developmental and endocrine aspects of normal ovarian aging. Molecular and Cellular Endocrinology 145 67-73.

te Velde ER, Dorland M \& Broekmans FJ 1998bb Age at menopause as a marker of reproductive ageing. Maturitas 30 119-125.

van Rooij IA, Broekmans FJ, te Velde ER, Fauser BC, Bancsi LF de Jong FH \& Themmen APN 2002 Serum anti-Mullerian hormone levels: a novel measure of ovarian reserve. Human Reproduction 17 3065-3071.

van Rooij IA, Tonkelaar I, Broekmans FJ, Looman CW, Scheffer GJ de Jong FH, Themmen APN \& te Velde ER 2004 Anti-mullerian hormone is a promising predictor for the occurrence of the menopausal transition. Menopause 11 601-606.

van Rooij IA, Broekmans FJ, Scheffer GJ, Looman CW, Habbema JD, de Jong FH, Fauser BJ, Themmen APN \& Te Velde ER 2005 Serum antimullerian hormone levels best reflect the reproductive decline with age in normal women with proven fertility: a longitudinal study. Fertility and Sterility 83 979-987.

Vendola K, Zhou J, Wang J, Famuyiwa OA, Bievre M \& Bondy CA 1999 Androgens promote oocyte insulin-like growth factor I expression and initiation of follicle development in the primate ovary. Biological Reproduction 61 353-357.

Vendola KA, Zhou J, Adesanya OO, Weil SJ \& Bondy CA 1998 Androgens stimulate early stages of follicular growth in the primate ovary. Journal of Clinical Investigation 101 2622-2629.

Visser JA 2003 AMH signaling: from receptor to target gene. Molecular and Cellular Endocrinology 211 65-73.

Webber LJ, Stubbs S, Stark J, Trew GH, Margara R, Hardy K \& Franks S 2003 Formation and early development of follicles in the polycystic ovary. Lancet 362 1017-1021.

Weenen C, Laven JS, Von Bergh AR, Cranfield M, Groome NP, Visser JA, Kramer P, Fauser BC \& Themmen APN 2004 Anti-Mullerian hormone expression pattern in the human ovary: potential implications for initial and cyclic follicle recruitment. Molecular Human Reproduction 10 77-83.

Received 21 July 2005

First decision 30 August 2005

Revised manuscript received 31 August 2005

Accepted 26 September 2005 